\title{
A ADOÇÃO DE SOFTWARES LIVRES PELAS DIVERSAS ESFERAS DA ADMINISTRAÇÃO PÚBLICA: ALGUNS ASPECTOS JURÍDICOS DE UM AMBIENTEDE DISPUTAS ECONÔMICAS
}

\author{
Marcelo Andrade Féres
}

\section{RESUMO}

Partindo de algumas notícias sobre o surgimento e a evolução do software livre, bem assim de sua classificação como um negócio jurídico peculiar, que concede ao usuário de um programa de computador o direito de alterá-lo, reproduzi-lo e redistribuí-lo, o presente estudo tem por objeto a análise da prioridade que as diversas esferas da Administração Pública devem dar a tal sorte de negócio, quando da contratação de programas informáticos.

Palavras-Chaves: Software livre; Administração Pública; contratação de programas informáticos.

\begin{abstract}
Leaving of some news about the appearance and the evolution of the free software, well like this of the classification as a peculiar legal transaction, that it grants to the user's computer program the right of altering, to reproduce and to redistribute the programe, the objective of the present work is to analyse the priority that the several spheres of the Public Administration should give this hind of business, when of the contracting of informatics programs.
\end{abstract}

Keywords: Free software; Public Administration; contracting of informatics programs. 


\section{Introdução}

A revolução tecnológica que avassala o espírito dos sujeitos da sociedade contemporânea alastra-se não apenas sobre o cenário privado, mas também sobre o público. Se o modo de agir individual modifica-se e, de certa maneira, codifica-se pelas formatações binárias dos computadores e da web, é certo que o Estado não pode orientar sua atuação à margem dessa realidade.

Não se discute mais se a Administração Pública deve ou não se valer dos meios tecnológicos; se deve ou não se informatizar. O debate atual refere-se, sim, à escolha que o Estado, em qualquer de suas esferas, deve fazer entre as várias opções existentes no mercado.

Nesse contexto, com atenção especial à forma de contratação de softwares pela Administração, surge a disputa entre os programas livres e os proprietários. Trata-se, entretanto, de tema cuja difusão se notabiliza em diversas searas do saber, como, v.g., na economia, na administração, na política, na sociologia e, naquilo que interessa ao presente estudo, no direito.

Os debates têm sido tão acirrados que até o Supremo Tribunal Federal foi convocado a se pronunciar. Cuida-se da Ação Direta de Inconstitucionalidade $n^{\circ}$ 3.059, proposta pelo Partido da Frente Liberal - PFL, tendo por objeto a Lei $\mathrm{n}^{\circ} 11.871^{1}$, de 19

\footnotetext{
${ }^{1}$ Veja-se o inteiro teor da lei impugnada na ADI $\mathrm{n}^{\circ}$ 3.059, in verbis: "Art. $1^{\circ} \mathrm{A}$ administração pública direta, indireta, autárquica e fundacional do Rio Grande do Sul, assim como os órgãos autônomos $e$ empresas sob controle do Estado utilizarão preferencialmente em seus sistemas e equipamentos de informática programas abertos, livres, de restrições proprietárias quanto a sua cessão, alteração $e$ distribuição.

$\S 1^{\circ}$ Entende-se por programa aberto aquele cuja licença de propriedade industrial ou intelectual não restrinja sob nenhum aspecto da cessão, distribuição, utilização ou alteração de suas características originais, assegurando ao usuário acesso irrestrito e sem custos adicionais ao seu código fonte, permitindo a alteração parcial ou total do programa para seu aperfeiçoamento ou adequação.

$\S 2^{\circ}$ Para fins de caracterização do programa aberto, o código fonte deve ser o recurso preferencial utilizado pelo programador para modificar o programa, não sendo permitido ofuscar sua acessibilidade, nem tampouco introduzir qualquer forma intermediária como saída de um pré-processador ou tradutor. $\S 3^{\circ}$ Quando da aquisição de softwares proprietários, será dada preferência para aqueles que operem em ambiente de multiplataforma, permitindo sua execução sem restrições em sistemas operacionais baseados em software livre.

$\S 4^{\circ}$ A implantação da preferência prevista nesta lei será feita de forma paulatina, baseada em estudos técnicos e de forma a não gerar perda de qualidade nos serviços prestados pelo Estado.

Art. $2^{\circ}$ As licenças de programas abertos a serem utilizados pelo Estado deverão, expressamente, permitir modificações e trabalhos derivados, assim como a livre distribuição destes nos mesmos termos da licença do programa original.

Parágrafo único - Não poderão ser utilizados programas cujas licenças:

I - impliquem qualquer forma de discriminação a pessoas ou grupos;

II - sejam específica para determinado produto, impossibilitando que programas derivados deste tenham a mesma garantia de utilização, alteração, distribuição; $e$

III - que restrinjam outros programas distribuídos conjuntamente.
} 
de dezembro de 2002, que “Dispõe sobre a utilização de programas de computador no Estado do Rio Grande do Sul”, e na qual houve concessão de medida liminar.

Naquele feito, sustenta o partido requerente que o mencionado diploma violaria os arts. 22, XXVII (necessidade de normas gerais de licitação e contratação editadas pela União), art. 37, caput e inciso XXI (princípio da impessoalidade e garantia de igualdade de condições dos concorrentes em licitações), 37, caput (princípios da eficiência e da economicidade), e $2^{0}$ e 61 , II, $b$ (princípio da separação de poderes e vício de iniciativa), todos da Constituição da República. Com a petição inicial, juntou-se aos autos parecer elaborado por Miguel Reale Júnior, Professor Titular da Faculdade de Direito da Universidade de São Paulo, dando suporte a parte das alegações do autor.

A argumentação expendida pelo PFL é aquela normalmente utilizada pelos adversários dos softwares livres, mas, com a devida vênia, sem o correto conhecimento de causa.

O presente texto, assim, objetiva trazer ao conhecimento do leitor algumas notícias sobre a evolução dos programas abertos, as vantagens que oferecem, bem como demonstrar, juridicamente, a sua idoneidade perante os objetivos da Administração Pública, tudo conforme se desenvolve nas linhas que seguem.

\section{Algumas notícias sobre o software livre no mundo e no Brasil: surgimento, evolução e relacionamento com a Administração Pública}

O software livre, decorrente do inglês free software, revela-se na liberdade que sua licença confere ao respectivo usuário. A origem estrangeira da expressão, em que se poderia colher uma ambivalência, tanto programa livre, quanto

Art. $3^{o}$ Será permitida a contratação e utilização de programas de computador com restrições proprietárias ou cujas licenças não estejam de acordo com esta Lei, nos seguintes casos:

I - quando o software analisado atender a contento o licitado ou contratado, com reconhecidas vantagens sobre os demais softwares concorrentes, caracterizando um melhor investimento para o setor público.

II - quando a utilização de programa livre e/ou código de fonte aberto causar incompatibilidade operacional com outros programas utilizados pela administração.

Art. $4^{\circ}$ O Estado regulamentará as condições, prazos e formas em que fará a transição, se necessária, dos atuais sistemas e programas de computador para aqueles previstos no art. $1^{o}$, quando significar redução de custos a curto e médio prazo, e orientará as licitações e contratações, realizadas a qualquer título, de programas de computador.

Parágrafo único - A falta de regulamentação não impedirá a licitação ou contratação de programas de computador na forma desta Lei.

Art. $5^{\circ}$ Esta Lei entra em vigor na data de sua publicação.

Art. $6^{\circ}$ Revogam-se as disposições em contrário." 
programa grátis, tem levado algumas pessoas a se confundirem, adotando a segunda tradução, o que é incorreto. Essa modalidade de software, também conhecida por aberto ou não proprietário, e em oposição ao fechado ou proprietário, não é necessariamente gratuito. ${ }^{2}$ Seu nome, assim, evidencia as liberdades dela decorrentes, pois a sua licença, aliada ao conhecimento de seu código fonte, além de permitir o uso para qualquer propósito, autoriza a reprodução, a alteração e a redistribuição.

No início, os softwares não eram comercializados; eram entregues pelos fabricantes juntamente com os poucos computadores que existiam. Com a evolução dos sistemas e o surgimento da diversidade de hardwares, os programas ingressaram no âmbito de tutela do direito autoral e, por conseqüência, passaram a ser negociados no mercado, que muitas vezes é monopolista.

O aparecimento do software livre está vinculado a uma relativização dos direitos autorais, em prol do desenvolvimento da sociedade. Ao lado da internet, os programas abertos concorrem para a disseminação da informação. Por seu intermédio, busca-se a tão almejada inclusão digital dos cidadãos. O conhecimento do código fonte dos programas, socialmente compartilhado, gera idôneas possibilidades de concreta participação do indivíduo no mundo contemporâneo da informática.

A adoção de software livre acarreta uma capilarização do desenvolvimento tecnológico, pois pequenas e médias empresas, além de indivíduos, conhecedores dos respectivos códigos, podem concorrer para a melhoria e o incremento da diversidade de programas disponíveis no mercado.

Com efeito, essa possibilidade de agregação de novas funcionalidades e, portanto, de novos valores aos softwares não proprietários, aquece o cenário econômico doméstico dos países em desenvolvimento, uma vez que se criam oportunas alternativas de trabalho.

A ampla propagação dos programas abertos deu vida a diversas organizações, cuja função é justamente estudar, desenvolver e difundir os conhecimentos sobre o assunto. Nessa linha, destacam-se a Free Software Foundation FSF e suas ramificações espalhadas pelo mundo, como, por exemplo, a Free Software

\footnotetext{
${ }^{2}$ Como assinala Joaquim Falcão, Diretor da Escola de Direito da Fundação Getúlio Vargas e Professor de Direito Constitucional da UERJ, in verbis: "Mas afinal o que realmente que um software é livre? O que é software livre? Na verdade, essa é a tradução de uma expressão americana: free software. Acontece que, em inglês, a palavra free pode significar tanto livre como grátis. Essa distinção é fundamental para colocar um pouco de bom senso no crescente e saudável debate entre o software livre e o software proprietário no Brasil e no mundo.” (Livre ou gratuito? Disponível em: www.femperj.org.br/jornal/05062004.htm; acesso em 12/11/2004).
} 
Foundation Europa e a Free Software Foundation France - FSF France. Merecem referência também a Association Francophone des utilisateurs de Linux et des logiciels libres - AFUL e a Associação Nacional para o Software Livre - ANSOL, esta última de Portugal. A par delas, no Brasil, há também diversas outras.

Várias entidades estrangeiras e nacionais têm migrado seus sistemas tecnológicos para softwares livres. A esse respeito, Luciano Alberto Rocho, em trabalho de conclusão do Curso de Especialização em Desenvolvimento Gerencial, do Departamento de Administração da Universidade de Brasília, escreve, in verbis:

"Hoje grandes corporações, tais como a General Motors e a Boeing, ou mesmo órgãos governamentais como a Nasa ou grande parte do governo francês são usuários de software livre, tendo em vista não só a economia, mas também total domínio na tecnologia envolvida, possibilitando a auditoria sobre todos os passos realizados por determinado programa que por muitas vezes é impossível quando se adquire um software vendido comercialmente."3

Com respeito à propagação dos softwares livres entre as empresas nacionais, recente matéria divulgada pela Revista Info, da Editora Abril, noticia que “De 2001 para cá, a área de internet da Varig deu vários vôos no mundo livre. Adotou o SAP DB como banco de dados; o Nagios, o Ntop e o NMIS no gerenciamento da rede; o Apache nos servidores web; o Firewall Builder como firewall; o software de atendimento de chamados RT (Request Tracker) no call center; o Jabber nas mensagens instantâneas; o Mozilla em parte dos desktops. 'Em três anos, queremos ser 100\% software livre na área de internet. Já temos pelo menos 30 sistemas rodando em cima desse tipo de programa', afirma Pinho."4 A mesma fonte informa que a companhia de aviação estima economizar cerca R\$ 12.000.000,00 (doze milhões de reais) por ano em virtude da medida.

Além da VARIG, a reportagem elenca outras empresas que utilizam programas livres, como, v. g., a EMBRAPA, os sucos Mais e a Petrobrás.

O papel do governo no cenário do software livre também é fundamental. Como assinala Roberto A. Hexsel, do Departamento de Informática da Universidade Federal do Paraná, litteris:

\footnotetext{
${ }^{3}$ ROCHO, Luciano Alberto. Software livre como alternativa viável na câmara dos deputados. Brasília: 2003, p. 08.

${ }^{4}$ O fenômeno do software livre. In: Revista Info. Editora Abril: fevereiro de 2004, p. 61.
} 
"Para que se desfrute das vantagens da utilização do software livre e se alcance os objetivos já enumerados, os governos devem executar as ações listadas abaixo. As três primeiras ações estabelecerão um mercado fornecedor e consumidor de software livre, a quarta e a quinta eliminarão a dependência do governo de práticas monopolistas, e as três últimas reforçarão os efeitos das outras ações.

1. Incentivo e recomendação ao uso de software livre em todas as situações em que seu uso não seja inviável;

2. uso do poder de compra para criar padrões de fato;

3. implantação de mecanismos de financiamento e incentivos fiscais ao uso e desenvolvimento;

4. adoção prioritária de protocolos abertos de comunicação;

5. retenção de direitos sobre o código fonte de todo o software adquirido pelo governo;

6. implantação de mecanismos de capacitação ao uso;

7. criação de agência para facilitar a adoção $e$ desenvolvimento de software livre; $e$

8. avaliação do impacto econômico e social da produção $e$ utilização de software livre no país. "

Nessa linha, especificamente quanto ao emprego de programas abertos no setor público, vários são os ordenamentos que o contemplam ou, ao menos, intencionam contemplar, o que se constata pelo infinito número de leis e de projetos legislativos em tramitação no mundo contemporâneo. A título ilustrativo, mencionemse, entre outros, os Projetos de Lei $n^{0}$ 5613-D-00 (Dragan) e $\mathrm{n}^{0}$ 904-D-02 (Dragan, Becerra \& Bertone), ambos da Argentina; a Lei $n^{0}$ 1416-D-02 (Caram), da cidade de Buenos Aires; a Proposition d'ordennance relative à l'utilisation de logiciels libres dans les administrations régionales de Bruxelle-Capitale, na Bélgica; o Projeto de Lei $n^{0}$ 122/000217 (Puigcercós et Boixassa), da Espanha; a Proposition de Loi 117 (Laffitte, Trégouet, Cabanel), a Proposition de Loi 2437 (Le Déaut, Paul, Cohen) e o Decrét 2001-737 (Premier Ministre Jospin), todos três da França; o Projeto de Lei S.1188 (Cortiana), da Itália; a Motion approuvée le 11/07/2001 (papini, Basosi, Menci, Pettini, Malavolti), de Florença, e a Motion approuvée le 18/3/2002 (Ugetti), de Lodi, ambas cidades italianas; os Projetos de Lei nº 1609/2001 (Villanueva Nuñez), no 2344/2002 (Estrada Perez), e n 2485/2002 (Villanueva Nuñez, Rodrich Ackerman), todos três do Peru; e o Projeto de Lei $n^{0}$ 126/IX (Drago, Louçã, Teixeira Lopes), de Portugal. ${ }^{6}$ No site chileno sobre software libre, em data recente, estampou-se notícia a

\footnotetext{
${ }^{5}$ HEXSEL, Roberto A. Software livre: Propostas de ações de governo para incentivar o uso do software livre. Curitiba, 2002, p.1.
} 
respeito também da Venezuela, segundo a qual “o Presidente da República, Hugo Chávez Frías, anunciou que emitirá um decreto mediante o qual se estabelecerá a utilização de software livre para todos os organismos e dependências da administração pública."7

Com relação às razões que levam a Administração Pública à adoção de softwares não proprietários, comporta assinalar alguns trechos da exposição de motivos que acompanhou o projeto de lei sobre sua utilização pelas instituições do Peru, em que o congressista Edgar Villanueva Núñez explica:

"Para garantir o livre acesso dos cidadãos à informação pública, resulta indispensável que a codificação dos dados não esteja ligada a um único provedor e menos a formatos não standard que alguns provedores impõem em virtude de suposto 'domínio' no mercado. $O$ uso de formatos standard e abertos permite garantir este livre acesso à informação independentemente se o provedor deseja ou não continuar os serviços, logrando se fosse necessário a criação de programa compatível com todo software que repete o standard mundial da indústria.

Para garantir a perenidade dos dados públicos, é indispensável que a utilização e a manutenção do software não dependam da boa vontade dos provedores, nem das condições monopolistas, impostas por estes. Necessita-se de sistemas cuja evolução natural possa ser garantida graças à disponibilidade do código-fonte.

Para garantir a segurança nacional, resulta indispensável contar com sistemas desprovidos de elementos que permitam o controle a distância ou a transmissão não desejada de informação a terceiros. Portanto, reclamam-se sistemas cujo código-fonte seja livremente acessível ao público para permitir seu exame pelo próprio Estado, por cidadãos e por um grande número de especialistas independentes no mundo." 8

\footnotetext{
${ }^{6}$ Essas informações foram retiradas do site da Association Francophone des Utilisateurs de Linux et des Logiciels Libres (Disponível em: www.aful.org/politique/references.html; acesso em: 21/11/04).

7 Tradução livre do original: "El presidente de la República, Hugo Chávez Frías, anunció que el Gobierno emitirá un decreto mediante el cual se establecerá la utilización de software libre para todas los organismos y dependencias de la administración pública." (Disponível em: www.softwarelibre.cl/modules.php?op=modload\&name=News\&file=article\&sid=411; $\quad$ acesso em: 21/11/2004).

${ }^{8}$ Tradução livre do original: "Para grantizar el libre acceso de los ciudadanos a la información pública, resulta indispensable que la codificación de los datos no esté ligada a un único proveedor y menos a formatos no estándar que algunos proveedores imponen por supuesto 'dominio' en el mercado. El uso de formatos estándar y abiertos permite garantizar este libre acceso a la información independentemente de si el proveedor desea o no continuar brindando los servicios, logrando si fuera necessario la creación de software compatible a todo software que respete el estándar mundial de la industria. Para garantizar la perenidad de lod datos públicos, es indispensable que la utilización y el mantenimiento del software no dependan de la buena voluntad de los proveedores, ni delas condiciones monopólicas, impuestas por éstos. Se precisan sistemas cuya evolución natural pueda ser garantizada gracias a la disponibilidad del código fuente. Para garantizar la seguridad nacional, resulta indispensable contar con sistemas
} 
Nas justificativas constantes do Projeto de Lei $n^{0}$ 126/IX, apresentado à Assembléia da República Portuguesa pelos deputados Ana Drago, Francisco Louçã e João Teixeira Lopes, referente à adoção de softwares abertos pela Administração Pública, há menção à escravidão tecnológica experimentada pelos Estados contemporâneos, cujos termos merecem ser transcritos a seguir:

"Hoje, apesar das alternativas, o Estado mantém-se refém de relações contratuais que lhe são desfavoráveis com as empresas de software. O software utilizado pela generalidade dos serviços do Estado não permite o acesso ao código-fonte, tanto do sistema operativo quanto das aplicações, implicando uma total impossibilidade de controlo, por parte do Estado, sobre a tecnologia usada para gerir a informação disponível em suporte digital. Os riscos de existência, quando se trata de software não livre, de <portas traseiras>, no que toca à segurança da informação, são hoje evidentes. O Estado não tem qualquer garantia em relação ao possível reencaminhamento da sua informação para outros. Mais: o Estado está dependente do seu fornecedor, num sector cada vez mais monopolizado, para aceder à sua própria informação. A situação actual põe em causa a própria soberania do Estado. As constantes modificações e contratos de upgrade feitas com os fornecedores acentuam e perpetuam a dependência tecnológica em relação ao fabricante." 9

Relativamente aos menores custos da utilização dos programas abertos pelo Estado, cumpre, novamente, mencionar a exposição de motivos do Projeto de Lei $\mathrm{n}^{\mathrm{o}}$ 126/IX, de Portugal, in verbis:

"Apesar do investimento inicial no processo migratório e na formação, os custos do software livre prolongam a vida útil dos computadores em uso e exige menos actualizações (quantas vezes desnecessárias) que, aumentando os custos, raramente correspondem às necessidades específicas dos utilizadores.

(...)

O investimento na migração (mudança de sistema) é o mais significativo. Mas se isto é verdade em relação à mudança para o software livre, é igualmente verdade para a mudança de um software não livre para outro." 10

\footnotetext{
desprovistos de elementos que permitan el control a distancia o la transmisión no deseada de información a terceros. Por lo tanto, se requieren sistemas cuyo código fuente sea libremente accesible al público para permitir su examen por el proprio Estado, los ciudadanos y un gran número de expertos independientes en el mundo." (Disponível em: www.softwarelibre.cl/modules.php?op=modload\&name=Downloads\&file=index\&req=viewdownload\&c id=17; acessado em: 21/11/04).

${ }^{9}$ Disponível em: http://www3.parlamento.pt/plc/iniciativa.aspx?id_ini=19247; Acesso em: 20/11/04.

${ }^{10}$ Disponível em: http://www3.parlamento.pt/plc/iniciativa.aspx?id ini=19247; Acesso em: 20/11/04.
} 
Além disso, a migração dos sistemas de informação do setor público para softwares livres aumenta a demanda desses programas, gerando, no âmbito dos Estados, especialmente daqueles em desenvolvimento e que não detêm patentes tecnológicas, um incremento das oportunidades de emprego para a população. Como já anotado, notabiliza-se que pequenas e médias empresas passam a concorrer em igualdade de condições com as grandes multinacionais, detentoras dos registros de programas proprietários.

No Brasil, a iniciativa do Estado do Rio Grande do Sul, contestada pelo PFL na ADI no 3.059, não é isolada. Anteriormente, o Município de Campinas/SP já havia adotado a Lei $\mathrm{n}^{0} 11.113$, de 27 de dezembro de 2001, que "Dispõe sobre a utilização de programa e sistema de computador aberto pela prefeitura municipal”, nos mesmos moldes da legislação ora impugnada. Esse caminho também foi trilhado pelo Município de Recife/PE, pela Lei $n^{0}$ 16.639/2001. Ademais, diversos projetos de lei encontram-se em tramitação no Congresso Nacional, valendo destacar os de $\mathrm{n}^{0}$ 2.269/1999, $\mathrm{n}^{0} 3.051 / 2000, \mathrm{n}^{0} 4.275 / 2001, \mathrm{n}^{0}$ 7.120/2002, $\mathrm{n}^{0} 2.152 / 2003$, e $\mathrm{n}^{0}$ $3.280 / 2004$.

Não fosse o bastante, aquela normativa gaúcha vem atender os termos da Lei Federal $n^{\circ}$ 7.232, de 29 de outubro de 1984, que “Dispõe sobre a Política Nacional de Informática, e dá outras providências”, e, em seu art. $2^{\circ}$, estabelece, in verbis:

“Art. $2^{\circ}$ A Política Nacional de Informática tem por objetivo a capacitação nacional nas atividades de informática, em proveito do desenvolvimento social, cultural, político, tecnológico e econômico da sociedade brasileira, atendidos os seguintes princípios:

I - ação governamental na orientação, coordenação $e$ estímulo das atividades de informática;

II - participação do Estado nos setores produtivos de forma supletiva, quando ditada pelo interesse nacional, e nos casos em que a iniciativa privada nacional não tiver condições de atuar ou por eles não se interessar;

III - intervenção do Estado de modo a assegurar equilibrada proteção à produção nacional de determinadas classes e espécies de bens e serviços bem assim crescente capacitação tecnológica;

IV - proibição à criação de situações monopolísticas, de direito ou de fato; 
$V$ - ajuste continuado do processo de informatização às peculiaridades da sociedade brasileira;

VI - orientação de cunho político das atividades de informática, que leve em conta a necessidade de preservar $e$ aprimorar a identidade cultural do País, a natureza estratégica da informática e a influência desta no esforço desenvolvido pela Nação, para alcançar melhores estágios de bem-estar social;

VII - direcionamento de todo o esforço nacional no setor, visando ao atendimento dos programas prioritários do desenvolvimento econômico e social e ao fortalecimento do Poder Nacional, em seus diversos campos de expressão;

VIII - estabelecimento de mecanismos e instrumentos legais e técnicos para a proteção do sigilo dos dados armazenados, processados e veiculados, do interesse da privacidade e de segurança das pessoas físicas e jurídicas, privadas e públicas;

IX - estabelecimento de mecanismos e instrumentos para assegurar a todo cidadão o direito ao acesso e à retificação de informações sobre ele existentes em bases de dados públicas ou privadas;

$X$ - estabelecimento de mecanismos e instrumentos para assegurar o equilibrio entre os ganhos de produtividade $e$ os níveis de emprego na automação dos processos produtivos;

$X I$ - fomento e proteção governamentais dirigidos ao desenvolvimento de tecnologia nacional e ao fortalecimento econômico-financeiro e comercial da empresa nacional, bem como estímulo à redução de custos dos produtos e serviços, assegurando-lhes maior competitividade internacional.”

É, pois, nesse contexto do mundo globalizado e da política nacional, que o debate acerca da adoção de softwares livres pelas diversas esferas da Administração Pública deve ser analisado.

\section{Da correta situação do negócio do software livre no âmbito da concretização dos princípios fundamentais da República Federativa do Brasil}

Nas linhas imediatamente anteriores, percebeu-se o positivo e paulatino crescimento mundial da utilização de programas abertos pelas diversas esferas nacionais e estrangeiras da Administração Pública, o que gerou o atual fenômeno da efervescência 
legislativa sobre a matéria. Diferentemente de outros assuntos jurídicos, cuja propagação ou, por assim dizer, a tropicalização, demanda alguns anos ou algumas dezenas deles, os temas referentes à sociedade da informação desenvolvem-se em uma perspectiva globalizada e sincrônica, assumindo importância ímpar o papel do operador do direito. A notória falta de experiência legislativa dos Estados a respeito de determinados domínios jurídicos, decorrente desse assinalado progresso simultâneo vivenciado por todo o mundo, reclama cautelas redobradas do intérprete das normas.

A propósito, o alemão Karl Larenz, em sua conhecida obra intitulada “Metodologia da Ciência do Direito”, leciona que:

\begin{abstract}
"<Interpretar> é, como tínhamos dito (cap. I, em 3a), <uma actividade de mediação, pela qual o intérprete traz à compreensão o sentido de um texto que se lhe torna problemático $>$. O texto da norma torna-se problemático para quem a aplica atendendo à aplicabilidade da norma precisamente a uma situação de facto dessa espécie. Que o significado preciso de um texto legislativo seja problemático depende, em primeira linha, do facto de a linguagem corrente, de que a lei se serve em grande medida, não utilizar, ao contrário de uma lógica axiomatizada e da linguagem das ciências, conceitos cujo âmbito esteja rigorosamente fixado, mas termos mais ou menos flexíveis, cujo significado possível oscila dentro de uma larga faixa e que pode ser diferente segundo as circunstâncias, a relação objectiva e o contexto do discurso, a colocação da frase e entoação de uma palavra. Mesmo quando se trata de conceitos em alguma medida fixos, estes contêm frequentemente notas distintivas que, por seu lado, carecem de uma delimitação rigorosa. "11
\end{abstract}

Com a intenção de aclarar o conteúdo do que se entende sobre software livre, deve-se partir da Lei Federal n 9.609/98, a qual “Dispõe sobre a proteção da propriedade intelectual de programa de computador, sua comercialização no País, e dá outra providências", e que, em seu art. $1^{0}$, estabelece:

“Art. $1^{o}$ Programa de computador é a expressão de um conjunto organizado de instruções em linguagem natural ou codificada, contida em suporte físico de qualquer natureza, de emprego necessário em máquinas automáticas de tratamento da informação, dispositivos, instrumentos ou equipamentos periféricos, baseados em técnica digital ou análoga, para fazêlos funcionar de modo e para fins determinados.”

\footnotetext{
${ }^{11}$ LARENZ, Karl. Metodologia da ciência do direito. Lisboa: Calouste Gulbenkian, 1997, p. 439.
} 
Sob o prisma dessa disposição, softwares livres e proprietários são, na essência, a mesma coisa; ambos são programas de computadores, expressão de um conjunto organizado de instruções em linguagem natural ou codificada.

Todavia, há distinções entre as espécies. De fato, a diferença específica entre as modalidades mencionadas reside num aspecto particular. Como anota o Guide de choix et d'usage de licences de logiciels libres pour les administrations, editado pela Agence pour les Technologies de l'information et de la Communication das l'Administration - ATICA, da França, in verbis:

"De um ponto de vista jurídico, um programa livre é antes de tudo um programa protegido pelo direito autoral e submetido a uma licença que regulamenta e delimita os respectivos direitos $e$ obrigações. Freqüentemente oposto ao programa proprietário, que habitualmente não comporta nada além que o direito de uso, o programa livre dele se distingue pelos direitos mais importantes conferidos, pelo titular do programa, aos beneficiários da licença. Um programa livre é, portanto, sujeito ao direito do autor e ao código de propriedade intelectual. Sua licença permite, assim, a utilização de um programa, mas ela permite igualmente, ao beneficiário da licença, estudar o funcionamento do programa - o que é possível em certos casos e sob certas condições com o programa proprietário -, modificar o programa por sua própria conta e redistribuir as modificações por ele efetuadas o que é geralmente vedado com os programas proprietários." 12

Portanto, programas fechados e livres distinguem-se em razão direta dos direitos que conferem aos respectivos usuários, ou seja, cuida-se de negócios distintos, e não propriamente de tipos diversos de produtos ou de programas. Enquanto a licença do software proprietário autoriza apenas sua utilização pelo contratante, a do programa aberto permite, por meio do acesso ao correspondente código fonte, sua utilização, sua

\footnotetext{
${ }^{12}$ Tradução livre do original: "D’un point de vue juridique, un logiciel libre est avant tout un logiciel protégé par le droit d'auter et soumis à une licence qui le réglemente et en délimite les droits et obligations afférents. Souvent opposé au logiciel propriétaire, qui habituellement ne comporte que des droits d'usage, le logiciel libre s'en distingue par les droits plus importants accordés par l'auter du logiciel aux bénéficiaires de la licence. Un logiciel libre est donc bien soumis au droit d'auter et au code de la propriété intellectuelle. Sa licence permet ainsi d'utiliser un logiciel, mais elle permet également au bénéficiaire de la licence d'étudier le fonctionnement du logiciel - ce qui est parfois possible sous certaines conditions avec les logiciels propriétaires - de modifier le logiciel pour son usage propre et de redistribuer les modifications qu'il a effectuées sur le logiciel - ce qui est généralement interdit avec les logiciels propriétaires." (Guide de choix et d'usage de licences de logiciels libres pour les administrations.

Disponível

em:
} 
cópia, sua alteração e sua redistribuição. Essa tônica negocial nota-se, por exemplo, na lei do Estado do Rio Grande do Sul, questionada na Ação Direta de Inconstitucionalidade n. 3.059, in verbis:

“Art. $1^{\circ}(\ldots)$

$\S 1^{\circ}$ Entende-se por programa aberto aquele cuja licença de propriedade industrial ou intelectual não restrinja sob nenhum aspecto da cessão, distribuição, utilização ou alteração de suas características originais, assegurando ao usuário acesso irrestrito e sem custos adicionais ao seu código fonte, permitindo a alteração parcial ou total do programa para seu aperfeiçoamento ou adequação.”

No entanto, quando a entidade estatal elege o software livre como meio negocial para consecução do interesse público, as distinções em face do programa fechado fazem-se ainda mais nítidas. Ocorre que a forma particular de negócio, inerente aos programas abertos, dá densidade aos fundamentos do Estado brasileiro (à soberania, à cidadania e à dignidade da pessoa humana), bem como aproveita aos seus objetivos de “construir uma sociedade livre, justa e solidária” e "garantir o desenvolvimento nacional”. É que a relativização do direito de propriedade autoral consubstanciada no compartilhamento social do código fonte dos programas de computadores, subjacente à noção de software livre, ao fim e ao cabo, exprime o melhor e mais ostensivo atendimento ao princípio constitucional da função social da propriedade.

Aliás, de acordo com o que já se mencionou, o Estado tem um papel relevante na formação do ambiente de desenvolvimento dos softwares abertos. Ao elegê-los como instrumento de suporte à sua atuação, a entidade estatal vale-se de seu poder de compra para o incremento do correspondente mercado consumidor, o que, claramente, insere-se no âmbito do planejamento econômico. Mais precisamente, tratase de uma intervenção do ente público no domínio econômico para fomentar determinada sorte de atividade.

Finalmente, reduzir o debate da adoção do software aberto pelo setor público aos estreitos limites da licitação como pretendem os opositores - ainda que, no campo léxico, as sistemáticas normativas a ela se refira - significa desprezar a real dimensão do tema, consistente na democrática atuação da Administração Pública. Renegar essa perspectiva maior traduziria um desrespeito aos valores fundamentais da República Federativa do Brasil, quais sejam, a soberania, a cidadania, a dignidade da 
pessoa humana e os valores sociais do trabalho e da livre iniciativa, que apenas têm a ganhar concretude e densidade, em razão da preferência estabelecida por algumas normas estatais - como, por exemplo, a Lei $\mathrm{n}^{0}$ 11.871, de 19 de dezembro de 2002, do Estado do Rio Grande do Sul. Não fosse o bastante, tal redução significaria uma interdição sobre a faculdade que tem o Governo de ditar suas políticas econômicas.

\section{Da prescindibilidade de lei da União para que os Estados, o Distrito Federal e os Municípios possam disciplinar a adoção de free softwares}

Situado o negócio do software livre no contexto de realização dos princípios e objetivos da República Federativa do Brasil, cabe analisar o argumento normalmente suscitado pelos seus adversários, no sentido de que eventuais normas dos Estados, do Distrito Federal e dos Municípios afrontariam o disposto no art. 22, XXVII, da Carta Política ("Art. 22. Compete privativamente à União legislar sobre: (...) XXVII - normas gerais de licitação e contratação, em todas as modalidades, para as administrações públicas diretas, autárquicas e fundacionais da União, Estados, Distrito Federal e Municípios, obedecido o disposto no art. 37, XXI, e para as empresas públicas e sociedades de economia mista, nos termos do art. 173, $\S 1^{\circ}$, III; ”), isso é, elas careceriam da prévia existência de lei federal sobre a matéria.

De início, note-se que a Administração Pública sequer necessita de lei para optar preferencialmente pela adoção dos programas livres. Basta que, nos editais licitatórios, oriente-se pela forma de negócio de tais softwares.

De qualquer forma, eventual legislação dos Estados, dos Distrito Federal e dos Municípios não deve ser apreciada sob a perspectiva única das normas constitucionais da licitação, mas sim sob o enfoque de se tratar de diploma que revela a escolha estatal de perseguir os interesses públicos primários e secundários, bem como, consoante já assinalado - pedindo-se vênia ao leitor para insistir -, a atribuição de concretude aos princípios e aos objetivos da República.

Consoante destacado, a eleição de uma ou outra forma de negócio, programas livres ou proprietários, constitui opção única do Estado, que revela seu planejamento econômico. Insista-se: ao estabelecer a prioridade legal pelos softwares livres, o ente público emprega o seu poder aquisitivo para criar e fomentar o mercado consumidor desses programas. Cuida-se de típica matéria de intervenção do Estado na seara econômica, ou seja, de Direito Econômico (art. 174 e 24, I, ambos da Constituição 
da República), cuja legislação compete concorrentemente à União, aos Estados, ao Distrito Federal e aos Municípios, acarretando, no ambiente da questão em exame, a prescindibilidade de prévia edição de lei federal.

Entretanto, caso se opte por examinar a controvérsia sob aquele aspecto limitado, deve-se salientar, desde logo, que não existe a inconstitucionalidade sugerida pelos opositores dos free softwares.

A preferência pelos direitos emergentes do software livre há de ser orientada pelo interesse local, ou seja, não se exige nem se pode exigir que ela conste de norma geral editada pela União. A adoção de programas abertos pela Administração Pública norteia-se por uma série de fatores contingenciais e muito particulares, como, por exemplo, a existência e os limites de disponibilidades financeiras, o tempo, os recursos humanos, a proximidade do suporte tecnológico, tudo apontando para predominância do interesse local, o que força concluir que compete ao Estado, ao Distrito Federal e aos Municípios disciplinarem a matéria, independentemente de prévia legislação da União.

Ratificando esse entendimento, vale a lembrança de que parte significativa dos projetos relacionados ao emprego de softwares livres pelo setor público e que se encontram em tramitação no Congresso Nacional não se referem aos Estados nem ao Distrito Federal, tampouco aos Municípios, mas apenas à União. Para ilustrar, mencionem-se o Projeto de Lei $\mathrm{n}^{0}$ 3.051/2000, que "Determina a preferência $a$ sistemas e programas abertos na aquisição e uso de programas de computadores pelos órgãos da Administração Pública Federal”, de autoria do Deputado Werner Wanderer; o Projeto de Lei $n^{0} 4.275 / 2001$, que “Dispõe sobre a adoção de sistemas e programas de computador abertos pelos órgãos da Administração Pública Federal”, elaborado pelo Deputado Luiz Bittencourt; e o Projeto de Lei $n^{0} 2.152 / 2003$, “Determina a adoção de software livre em todos os órgãos e entidades públicas federais”, apresentado pelo Deputado Coronel Alves.

Aliás, leis estaduais, distritais ou municipais, nos estritos limites das respectivas competências apenas viriam a dar densidade ao princípio da padronização das compras, estatuído pelo art. 15, I, da Lei nº 8.666/93.

Dessa maneira, resta patente que quaisquer normas estaduais, distritais ou municipais que venham a fixar a preferência, nos correlatos âmbitos administrativos, pelo negócio do software aberto, não carece de prévia legislação da União sobre o tema, sendo, portanto, plenamente conforme a Carta da República. 


\section{Da não violação ao princípio da isonomia dos licitantes}

Ao lado de outras argumentações, os adversários da adoção do software livre pela Administração, suscitam que eventuais preferências legais não respeitariam o princípio da isonomia entre os licitantes, previsto no art. 37, XXI, da Constituição da República, o que também não procede.

Jorge Miranda, de Portugal, ao abordar o princípio da igualdade, leciona:

"Existe uma tensão insuprimível entre liberdade e igualdade (conforme, de resto, já salientámos): assim como a liberdade radical de certo individualismo, levada às últimas conseqüências, ignora a igualdade (pelo menos, a igualdade de exercício de direitos), a igualdade igualitária conduz à destruição da liberdade (pelo menos, da liberdade política). E torna-se recorrente nas sociedades pluralistas contemporâneas a procura de um equilíbrio tanto entre igualdade e aquilo a que se vem chamando direito à diferença como entre bens $e$ interesses de grupo."13

É esse direito à diferença, decorrente necessário do princípio da isonomia, que aproveita à compreensão do caso dos autos. No infinito universo da tecnologia informática, diferem-se radicalmente e, portanto, ostentam direito a tratamentos distintos os negócios de softwares livres e os de proprietários.

Com efeito, no ambiente normativo peculiar da licitação, no qual se prega a igualdade de condições entre os concorrentes, não viola a isonomia norma que estipula preferência por uma determinada forma negocial. Como já referido, a distinção levada a efeito por eventual norma de semelhante conteúdo não se direciona a um produto ou a um tipo de produto específico, mas sim a uma forma de contratação, revelando a vontade estatal de atribuir densidade a certos valores constitucionais.

Celso Antônio Bandeira de Mello, em sua clássica monografia sobre o “Conteúdo Jurídico do Princípio da Igualdade”, arrola critérios para que uma discriminação feita por lei não infrinja o princípio constitucional da isonomia, valendo a pena transcrever excerto de suas lições, in verbis:

\footnotetext{
${ }^{13}$ MIRANDA, Jorge. Manual de direito constitucional. Tomo IV. Coimbra: Coimbra Editora, 1993, pp. $201 / 202$.
} 
"Para que um discrímen legal seja convivente com a isonomia, consoante visto até agora, impende que concorram quatro elementos:

a) que a desequiparação não atinja de modo atual e absoluto, um só indivíduo;

b) que as situações ou pessoas desequiparadas pela regra de direito sejam efetivamente distintas entre si, vale dizer, possuam características, traços, nelas residentes, diferençados;

c) que exista, em abstrato, uma correlação lógica entre os fatores diferenciais existentes e a distinção de regime jurídico em função deles, estabelecida pela norma jurídica;

d) que, in concreto, o vínculo de correlação supra-referido seja pertinente em função dos interesses constitucionalmente protegidos, isto é, resulte em diferenciação de tratamento jurídico fundada em razão valiosa - ao lume do texto constitucional - para o bem público. $" 14$

Partindo desses parâmetros, primeiramente, cumpre apontar que a adoção preferencial dos programas abertos pela Administração Pública, não restringe as possibilidades de concorrência, nas respectivas licitações, a um único produto ou a um fornecedor singular. Para se ter uma idéia da diversidade de softwares livres existentes no mercado e, portanto, da variedade de produtos aptos a participarem dos certames, mencione-se o ranking apresentado na matéria “O fenômeno do Software Livre”, da Revista Info, relativo aos principais programas de códigos abertos utilizados pelas grandes empresas, quais sejam, LINUX, APACHE, TOMCAT, BIBLIOTECAS JAVA, PERL/PHP, JBOSS, APACHE STRUTS, MYSQL, ECLIPSE e outros. ${ }^{15}$ Ademais, é importante, neste particular, perceber que a distinção se trava entre as formas de negócios e não propriamente entre os programas. A rigor, ambos os programas negociados em regra distintamente, seja o proprietário, seja o não proprietário, são idôneos a concorrerem perante a Administração Pública, bastando para tanto que o titular daquele primeiro revele o seu código fonte e admita a respectiva reprodução, modificação e distribuição. Isso é, em termos práticos, todo e qualquer software pode ser negociado sob a forma livre, inclusive os conhecidos como proprietários.

Na seqüência dos parâmetros arrolados por Celso Antônio Bandeira de Mello, cabe perceber que as modalidades de programas em evidência são totalmente

\footnotetext{
14 MELLO, Celso Antônio Bandeira de. Conteúdo jurídico do princípio da igualdade. São Paulo: Malheiros, 1999, p. 41.

${ }^{15}$ O fenômeno do software livre. In: Revista Info. Editora Abril: fevereiro de 2004, p. 58.
} 
diferentes, não enquanto programas, mas com respeito à forma negocial que são disponibilizados aos usuários, ou seja, a diferença enquadra-se no plano da realidade objetiva, perceptível por qualquer pessoa.

Quanto à correlação lógica entre os fatores diferenciais existentes e a distinção de regimes, no caso, licitatórios, ela existe na hipótese em exame. O tratamento diferenciado justifica-se por tudo quanto já se expôs neste trabalho.

Por fim, a diferenciação traçada pela lei impugnada atende à concretização dos princípios e dos fundamentos da República Federativa do Brasil, conforme também já se demonstrou.

A propósito, não se pode olvidar que o debate do software livre também já chegou ao Tribunal de Contas da União, o qual entendeu possível a preferência ora em questão, desde que devidamente fundamentada (TC-004.193/01-1, In: Boletim de licitações e contratos, n. 2, fevereiro de 2004, p. 124 e ss.).

Dessa forma eventuais normas que atribuam prioridade à contratação de softwares livres pelo Estado não incidem em infringência ao princípio da isonomia entre os licitantes.

\section{Do software livre como principal meio de concretização do princípio constitucional da eficiência}

Entre outros obstáculos, normalmente se alega que a preferência legal pelo negócio do software livre infringiria o princípio da eficiência (art. 37, caput, da Constituição da República) e, também, o da economicidade.

Com efeito, desde a Emenda n ${ }^{0}$ 19/98, que carreou à Carta da República o princípio da eficiência, especificamente no caput do art. 37, de sorte a integrá-lo ao bloco de controle constitucional - de acordo com a linguagem portuguesa -, inaugurouse uma nova era da Administração Pública pátria. De uma gestão estatal que nasceu num contexto patrimonialista e passou por outro, o burocrático, chega-se ao cenário da eficiência, no qual se delineia um Estado enxuto, ágil e dinâmico, próximo das texturas econômicas do próprio setor privado.

Pois bem, se a opção pelos direitos emergentes dos programas abertos não se apresentasse como a melhor otimização de disponibilidades financeiras, bem como o meio mais seguro de desenvolvimento de atividades, sejam econômicas ou não, o ambiente empresarial, em que a correta alocação de recursos norteia a respectiva 
lógica, não os acolheria nem os estimularia. Se assim é no contexto do mercado, parece acertada, também, a preferência do Estado pelos softwares não proprietários.

Ao tecer considerações sobre a correlação entre o princípio da eficiência e o software livre, Ivo Teixeira Gico Júnior, mestre pela Columbia University (USA), esclarece:

"Da própria análise da definição de software livre podemos inferir suas vantagens sobre os demais tipos de software, os programas proprietários. Primeiro, a administração que o adota não se submete a qualquer condição ou restrição de uso que não aquele ditado pelo interesse público. Segundo, como o acesso ao código-fonte é permitido, ou seja, sabe-se o que está por trás do programa, qualquer um pode estudá-lo, adaptá-lo a suas necessidades particulares e melhorá-lo em caso de falhas. Sua adoção representa, em última análise, uma transferência de tecnologia. Por último, mas não menos importante, como não se paga pela licença do software livre, não só o custo de aquisição é nulo, como o de aquisição de equipamentos (hardware) é muito menor, uma vez que tais programas exigem menor capacidade de processamento. É aqui que o princípio da eficiência se faz sentir de maneira mais forte.

O mercado brasileiro de software movimentou mais de US\$ 3,2 bilhões em 2000. Dessa quantia, US\$ 1 bilhão refere-se à aquisição de licenças de software proprietário, sendo o governo federal responsável por mais de $R \$ 200$ milhões por ano. Uma vez que a adoção do software livre representa real possibilidade de redução de custos, da exegese do princípio da eficiência resta cogente sua adoção pela administração, independentemente de outros fundamentos como a democratização do conhecimento, desenvolvimento da indústria local, independência tecnológica, soberania, segurança nacional (já que é o único efetivamente auditável) e, com maior razão, se levarmos em consideração o tão propalado princípio da razoabilidade. "16

Não é, entretanto, apenas o argumento econômico que orienta a eficiência da opção pelos softwares abertos. Primeiramente, a segurança do armazenamento de informações e de dados públicos reclama o domínio dos códigos dos programas, bem assim a plena ciência dos trâmites correspondentes, sob pena de o Estado ver violados seus informes mais íntimos pela sua própria rede de tecnologia, acessível por "portas traseiras” - como fala o legislador português - unicamente pelo autor do programa fechado.

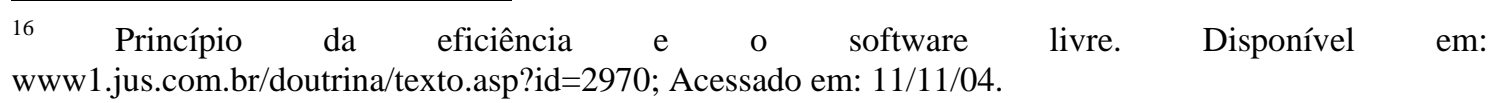


A par disso, consoante já mencionado, somente os softwares livres permitem a plena concretização do princípio democrático e da cidadania, por meio do compartilhamento do código fonte utilizado pelo ente estatal na consecução de certas tarefas, acarretando, assim, a transparência que deve permear a Administração. Ademais, essa socialização do código permite uma interação criativa entre o agente público e o programa, de modo a permitir uma total adequação deste às necessidades materiais do correlato órgão.

Vale apontar, ainda, que, em eventual inadimplemento do contratado pela Administração - para exemplificar, suponha-se que se negue a proceder à manutenção convencionada do programa adquirido -, apenas o software livre permitiria a encampação de que cuida o art. 58, V, da Lei $n^{0}$ 8.666/93. O segredo que permeia 0 código dos programas proprietários poderia comprometer, na hipótese, a continuidade do serviço público, o que, por certo, não sucederia com aqueles abertos.

A propósito, um dos obstáculos que alguns menos avisados levantam contra a economicidade e a eficiência da utilização de softwares livres pela Administração refere-se a uma suposta ausência de responsável por ocasionais vícios ou falhas dos sistemas. Trata-se de premissa equivocada, pois, ao licitar a aquisição de programas, o Estado poderá valer-se da faculdade de exigir do respectivo distribuidor as garantias necessárias à plena execução do objeto, nos termos do art. 54, VI, da Lei 8.666/93.

Com essas considerações, mostra-se inegável o fato de o software livre ser, no universo informático, o principal meio - e, talvez, até o único - capaz de atender tanto ao princípio da eficiência, quanto ao da economicidade.

Não apenas isso, os programas abertos, por todas as suas peculiaridades, constituem a necessária opção à qual deve proceder o Poder Público, cujos agentes efetivamente se pautam pela concretização dos valores estatuídos na Carta da República. 


\section{Referências}

ASSOCIATION FRANCOPHONE DES UTILISATEURS DE LINUX ET DES LOGICIELS LIBRES. [Home page]. Disponível em: <www.aful.org/politique/ references.html>. Acesso em: 21 nov. 2004.

GUIDE de choix et d'usage de licences de logiciels libres pour les administrations. Disponível em: <http://softwarelibre.cl/modules.php?op=modload\&name=Downloads\& file=index\&req=viewdownload\&cid=13>. Acesso em: 21 nov. 2004.

HEXSEL, Roberto A. Software livre: propostas de ações de governo para incentivar o uso do software livre. Curitiba: [s.n.], 2002.

LARENZ, Karl. Metodologia da ciência do direito. Lisboa: Calouste Gulbenkian, 1997.

LIVRE ou gratuito?. Disponível em: http://www.femperj.org.br/jornal/05062004.htm>. Acesso em: 12 nov. 2004.

MELLO, Celso Antônio Bandeira de. Conteúdo jurídico do princípio da igualdade. São Paulo: Malheiros, 1999.

MIRANDA, Jorge. Manual de direito constitucional. Coimbra: Coimbra Editora, 1993. t. 4.

O FENÔMENO do software livre. Info Exame, São Paulo, p. 61, fev. 2004.

EL PRESIDENTE de la República, Hugo Chávez Frías, anunció que el Gobierno emitirá un decreto mediante el cual se establecerá la utilización de software libre para todas los organismos y dependencias de la administración pública. Disponível em: $<$ http://www. softwarelibre.cl $/$ modules.php?op=modload $\&$ name $=$ News $\&$ file $=$ article $\&$ sid $=411>$. Acesso em: 21 nov. 2004.

PORTUGAL. Assembléia da República. Actividade parlamentar e processo legislativo. Disponível em:

<http://www3.parlamento.pt/plc/iniciativa.aspx?id_ini=19247>. Acesso em: 20 nov. 2004. 
Actividade parlamentar e processo legislativo. Disponível em:

$<$ http://www3.parlamento.pt/plc/iniciativa.aspx?id_ini=19247>. Acesso em: 20 nov. 2004.

PRINCÍPIO da eficiência e o software livre. Disponível em:

<www1.jus.com.br/doutrina/ texto.asp?id=2970>. Acesso em: 11 nov. 2004.

ROCHO, Luciano Alberto. Software livre como alternativa viável na Câmara dos Deputados. Brasília: [s.n.], 2003.

SOFTWARE LIBRE CHILE. [Home page]. Disponível em: <www.softwarelibre.cl/ modules.php?op=modload\&name=Downloads\&file=index\&req=viewdownload \&cid $=1$ 7>. Acesso em: 21 nov. 2004. 